\title{
Construction and Practice of Integrated Teaching Mode of Yoga Course in Colleges and Universities under Big Data
}

\author{
Li Min \\ Jiangxi Science \& Technology Normal University, Nanchang, Jiangxi, 330013
}

\begin{abstract}
Keywords: Big Data, Colleges and Universities, Yoga Courses, Integrated Teaching
\end{abstract}
\begin{abstract}
In recent years, yoga has springing up all over the world, and yoga courses have been set up in Colleges and universities in China. Yoga is a system of promoting the full potential of human beings by promoting consciousness. Based on the current situation of yoga teaching in the era of big data, this paper expounds the advantages and functions of constructing the integrated teaching mode of Yoga course in universities. The application of the integrated yoga teaching model is discussed in practice, in order to provide a reference for the construction of the integrated teaching model of yoga courses in Colleges and universities.
\end{abstract}

\section{Introduction}

Big data refers to massive, high growth rate and diversified information assets that require new processing mode to have stronger decision-making power, insight and process optimization capabilities. Yoga has been developed in India for thousands of years, and in recent years, yoga has sprung up again. The yoga posture uses the old and easy to master skills. The ability to improve people's physiological, psychological, emotional and spiritual aspects, so that the athletes to achieve the harmony of the body, mind and spirit [1-2]. Under the background of big data, yoga courses in universities and colleges adopt integrated teaching mode. They can use different teaching methods to achieve better teaching effect on the basis of understanding individual differences of students.

\section{The Present Situation of Yoga Course in Colleges and Universities under the Background of Large Data}

The era of big data has had a great impact on the field of education in China. The development of big data has created more convenient and efficient means of education for education reform, which has also had a serious impact on the traditional education mode. Modern college students are more and more capable of receiving information through the Internet [3]. They are influenced by the development of modern science and technology, and are more interested in interesting autonomous learning.

Yoga is the content of physical education system in Colleges and universities. Under the background of big data, the yoga teaching in universities should follow the results of big data analysis and statistics. Through the results of data analysis, students can understand individual differences, teach students in accordance with their aptitude, meet the needs of students, and improve the teaching effect of yoga courses in Colleges and universities [4].

In the traditional sports teaching system, it takes competitive sports as the main part and ignores the students' hobbies and their sexual development. Offering Yoga courses can enrich the content of college physical education, help students to have peace of mind, shape their posture, and eliminate the pressure and tension of college students in learning and coming into the society.

At present, more and more colleges and universities have set up yoga courses to teach students yoga postures. But in actual teaching, due to lack of professional yoga textbooks and yoga equipment, yoga teaching is also not systematic, leading to the failure of yoga teaching in Colleges and universities. At present, the teaching of yoga is usually based on the teachers' understanding of yoga and determines the content and methods of the teaching [5]. In yoga teaching, teachers focus on the teaching of yoga posture, lack of teaching of yoga theory knowledge, so that students only 
know their shape and meaning in yoga learning. Most of yoga teaching is teacher demonstration. Students imitate, do not play the main role and innovation consciousness of college students in learning, lack of application of modern technology and make students lack enthusiasm in learning.

\section{The Advantages and Functions of the Integrated Teaching Model of Yoga Courses in Large Data Colleges and Universities}

The integrated teaching mode combines practice teaching with theoretical teaching, constructs student's comprehensive quality ability as the training goal, formulating teaching plan and syllabus, and ensures the realization of the overall goal through the implementation of various teaching links. Under the background of large data, colleges and universities use integrated teaching mode to teach students the course of yoga [6]. The main advantages are as follows:

\subsection{It is beneficial to improve the teaching mode and promote the reform of Education}

The application of integrated teaching mode is the reform of traditional teaching mode, which can maximize the development of students' personality, combine the integrity and diversity of yoga courses, and improve the efficiency of yoga teaching. At the same time, it can make students use yoga after class, which is not only a course, but also can improve the physical quality and mental health of the students [7]. Through the implementation of the integrated teaching model, we can provide experience for the reform of education, improve the existing teaching mode and promote the improvement of teaching efficiency.

\subsection{It is beneficial to the integration of teaching and extracurricular teaching in order to improve the students' learning efficiency}

The use of integrated teaching mode in yoga courses is to combine classroom teaching with extracurricular sports training and integrate extracurricular activities into teaching activities. At the same time, in the background of large data, students can find the resources they need through multimedia network, and improve their lack of learning. Through data analysis of student characteristics, according to the characteristics of students, develop different teaching methods, improve students' learning enthusiasm, and ultimately achieve the goal of yoga curriculum.

\subsection{It is beneficial to meet the students' training needs and enhance the comprehensive quality of the students}

The purpose of integrated teaching is to improve the students' comprehensive quality and ability and to combine practical teaching with theoretical teaching. Under the integrated teaching model, students can choose the practical teaching methods according to their own needs. College students can get more free time for yoga through their own choice of practical teaching methods. It can give full play to the subjective initiative of college students and meet the training needs of college students [8]. At the same time, in the process of College Students' independent choice of practice, the ability of independent selection will also be improved, and finally the purpose of enhancing the comprehensive quality of the students is achieved.

\section{Construction and Practice of Integrated Teaching Model of Yoga Courses in Colleges and Universities}

\subsection{The construction of teaching environment and teaching system}

Yoga can improve people's ability in physiological, psychological, emotional and spiritual aspects. The teaching of yoga poses must have a good teaching environment. Colleges and universities in the yoga curriculum, must prepare professional yoga materials and equipment, through the use of professional yoga equipment ensure that students can get effective protection in the process of learning yoga, to protect the safety of students; through the use of professional yoga teaching materials, help teachers construct yoga teaching system, teaching system through.

We should form a complete teaching system in the university, build excellent teaching team, 
improve the quality of teachers and ensure that teachers can systematically teach students, help students in class and after class training. In the traditional yoga teaching mode, the teaching is carried out by the way of teacher demonstration and the imitation of the students [9-10]. A good teaching atmosphere should be formed in Colleges and universities to ensure that students can get good yoga teaching venues and learning fields, and cooperate with professional teachers, providing help for students in two aspects of yoga theory learning and practical learning.

\subsection{Diversity of teaching forms}

The integrated teaching activities of yoga curriculum should be carried out under the premise of combining the teaching plan and teaching goals of yoga courses in Colleges and universities. In the practical yoga teaching, not only should the students' action be standardized, but also the students' knowledge of Yoga needs to be enriched [11]. Because nonstandard yoga poses can cause physical damage to students when learning yoga, teachers also need to correct students' non-standard yoga posture and ensure the standardization of yoga poses.

At the same time, carry out appropriate Yoga Basic exercise training to ensure students' Yoga learning basis, so that students can achieve twice the result with half the effort in learning yoga. Using the theory of large data to analyze the students' learning situation, combine the theoretical content with the practice training, and enrich the teaching content of the Yoga course in Colleges and universities. In this way, we can not only promote the diversification of school teaching forms, but also enable schools to use appropriate teaching methods in teaching and promote the realization of teaching goals.

\subsection{Carry out extracurricular activities related to yoga}

In order to improve the students' enthusiasm for learning yoga, the extracurricular activities related to yoga can be held in Colleges and universities. For example, the establishment of a yoga interest Association and a yoga competition can not only meet the needs of the students' extracurricular training, but also improve the students' enthusiasm for learning yoga. Combined with modern teaching methods and teaching methods, it is beneficial to the combination of College Students' interest and study, and to improve the teaching effect of yoga courses in Colleges and universities.

Schools can also encourage students to organize various kinds of Yoga competitions and yoga activities on their own, so that students can make progress in the course of communication and competition and improve their yoga level. Giving full play to the subjective initiative of college students and the dominant position of college students in yoga teaching are conducive to the realization of educational system reform and the improvement of College Students' comprehensive quality.

\section{Conclusion}

In the era of big data, new requirements have been put forward to the teaching of yoga in Colleges and universities. Start yoga teaching in colleges should be based to stimulate students' interest in learning, the use of modern means, the use of integrated teaching mode in college yoga teaching, to promote teaching mode to perfect, promote education reform; promote the classroom teaching and the extracurricular teaching integration, improve the learning efficiency of the students, meet the students' needs to enhance students' comprehensive training; the quality of the. By constructing a perfect teaching environment and teaching system, adopting diversified teaching methods, developing various yoga related extracurricular activities, we can finish yoga teaching for college students, and ultimately achieve the purpose of enhancing students' comprehensive quality.

\section{References}

[1] Yang H L, Dong W U, University B S. Practice of Skills-Routine-Use with Integrated Teaching Model in Wushu Specific Course[J]. Journal of Beijing Sport University, 2016. 
[2] Shaobo F U, Zhao L, Yan Y U, et al. Exploration and Practice of Integrated Teaching Mode in Electrical Engineering Course[J]. Journal of Military Transportation University, 2016.

[3] Wang C F, Ling J, Yi J G, et al. Reflections on Primary Post Capacity-Oriented Integrated Practice Teaching of Oral Courses in Higher Vocational Colleges[J]. Lecture Notes in Electrical Engineering, 2014, 269:1463-1471.

[4] Zhan H L. Exploration and Practice on Integrated Course Teaching Mode in Higher Vocational Colleges[J]. Journal of Guangdong Communications Polytechnic, 2013.

[5] Lin-Lan H U, Song X Y, Cheng X Y. Construction of Virtual-Actual Integrated Teaching Mode of the Course "Machine Tool Fixture Design" in Higher Vocational Colleges[J]. Journal of Yangzhou College of Education, 2017.

[6] Yu W, Polytechnic G, University N N. Work-integrated Learning Teaching Practice of Higher Vocational Courses Based on the Post Ability[J]. Journal of Liaoning Higher Vocational, 2013.

[7] Cuiqing. Discussion on the Teaching Reform of Course Warehouse Management in Higher Vocational Colleges --, The Construction of Theory and Practice Courses Integrated Teaching Mode[J]. International Journal of Technology Management, 2013:75-77.

[8] Dong Y, Zhu X. Research of Teaching-Learning-Practicing Integrated Teaching Mode[M]// Informatics and Management Science V. Springer London, 2013:219-224.

[9] Hall M, Singh B R, Ames E, et al. Integrated learning in a science of Kriayoga course[J]. 2014, 3(1):55-65.

[10] Roth A L. Yoga as a Psychological Intervention: Conceptualizations and Practice Integration of Professional Psychologist-Yoga Teachers[J]. Dissertations \& Theses - Gradworks, 2014.

[11] Nosaka M, Okamura H. A Single Session of an Integrated Yoga Program as a Stress Management Tool for School Employees: Comparison of Daily Practice and Nondaily Practice of a Yoga Therapy Program[J]. Journal of Alternative \& Complementary Medicine, 2015, 21(7):444. 